\title{
LETTER
}

\section{X-ray diffraction study of high pressure transition in InOOH}

\author{
Asami SANO*, Takehiko Yagi", Taku OKADA*, Hirotada Gotou*, \\ Eiji OHTANI $^{* *}$, Jun TsUChIYA ${ }^{* * *}$, Takumi KIKEGAWA ${ }^{* * * *}$ \\ "Institute for Solid State Physics, The University of Tokyo, Kashiwa 277-8581, Japan \\ ${ }^{* *}$ Institute of Mineralogy, Petrology, and Economic Geology, Faculty of Science, \\ Tohoku University, Sendai 980-8578, Japan \\ ${ }^{* * *}$ Geodynamic Research Center, Ehime University, Matsuyama 790-8577, Japan \\ ${ }^{* * * *}$ Photon Factory, High Energy Accelerator Research Organization, \\ Tsukuba 305-0801, Japan
}

\begin{abstract}
We performed high-pressure and high-temperature $\mathrm{X}$-ray diffraction experiments on $\mathrm{InOOH}$ using laser heated diamond anvil cells. After heating at $1300 \mathrm{~K}$, pyrite-type InOOH was formed at $14 \mathrm{GPa}$ and it was stable up to at least $30 \mathrm{GPa}$. Pyrite-type InOOH partially transformed back to distorted rutile-type $\mathrm{InOOH}$ after recovery. The lattice constant and unit-cell volume of pyrite-type InOOH were determined to be $a_{0}=5.3151(8) \AA$ and $V_{0}=150.15(7) \AA^{3}$ at ambient conditions, respectively. The density difference between pyrite-type and distorted rutile-type $\mathrm{InOOH}$ was $5 \%$ at ambient condition.
\end{abstract}

Keywords: InOOH, Pyrite-type structure, High pressure

\section{INTRODUCTION}

Rutile-type structure is commonly found in $\mathrm{AX}_{2}$-type compounds and its high-pressure behavior has long been attracted. The general pathway of transition of $\mathrm{AX}_{2}$-type compounds with increasing pressure is as follows; rutile $\rightarrow$ distorted rutile $\left(\mathrm{CaCl}_{2}\right) \rightarrow \alpha-\mathrm{PbO}_{2} \rightarrow$ pyrite $\left(\mathrm{FeS}_{2}\right)$ (e.g., Léger et al., 1998). Coordination number increases from 6 to $6+2$ during these transitions. For example, $\mathrm{SiO}_{2}$, which is one of the important components of the earth's crust, undergoes transitions from stishovite to distorted rutile-type and then to $\alpha-\mathrm{PbO}_{2}$ structure at $50 \mathrm{GPa}$ (Kingma et al., 1995) and at $120 \mathrm{GPa}$ (Murakami et al., 2003), respectively. Pyrite-type $\mathrm{SiO}_{2}$ becomes stable at $268 \mathrm{GPa}$ (Kuwayama et al., 2005).

Oxyhydroxide $\left[\mathrm{M}^{3+} \mathrm{O}(\mathrm{OH})\right]$ such as $\alpha-\mathrm{FeOOH}$ (goethite) and $\alpha-\mathrm{AlOOH}$ (diaspore) found to takes diasporetype structure at ambient conditions, which is explained as a double-chained rutile-type framework. These compounds transforms into distorted rutile-type structure at high pressure. The distorted rutile-type structure of $\mathrm{FeOOH}$ is formed at $8 \mathrm{MPa}$ and $773 \mathrm{~K}$ in hydrothermal

doi:10.2465/jmps.071022m

A. Sano, sano@issp.u-tokyo.ac.jp Corresponding author study (Chenavas et al., 1973). $\alpha-\mathrm{AlOOH}$ transforms to distorted rutile-type phase, which is named as $\delta^{-} \mathrm{AlOOH}$, above $18 \mathrm{GPa}$ (Suzuki et al., 2000; Ohtani et al., 2001). This phase remains stable in the condition of the lower mantle, and no transition to higher-pressure phase was found even at $134 \mathrm{GPa}$ (Sano et al., 2008). Therefore it is not clear whether or not the oxyhydroxide follows common pathway of $\mathrm{AX}_{2}$-type compound. Theoretical studies predicted that in $\delta-\mathrm{AlOOH}$ a symmetric hydrogen bond is formed at $\sim 28-50 \mathrm{GPa}$ (e.g., Tsuchiya et al., 2002). The formation of symmetric hydrogen bond is expected to affect the physical properties such as compression behavior. Neutron diffraction study confirmed the existence of strong hydrogen bond in $\delta-\mathrm{AlOOH}$ (Vanpeteghem et al., 2007).

This work intends to explore the high-pressure polymorphs of distorted rutile-type oxyhydroxide having strong hydrogen bond in its structure. $\mathrm{InOOH}$ was selected because it is expected to have lower transition pressure than that of $\mathrm{AlOOH}$ due to the effect of chemical pressure. Distorted rutile-type $\mathrm{InOOH}$ was first synthesized by hydrothermal method at $973-1073 \mathrm{~K}$ and $2.5-5 \mathrm{GPa}$ by Christensen (1971). The neutron diffraction study has clarified that the distorted rutile-type $\mathrm{InOOH}$ is isostruc- 


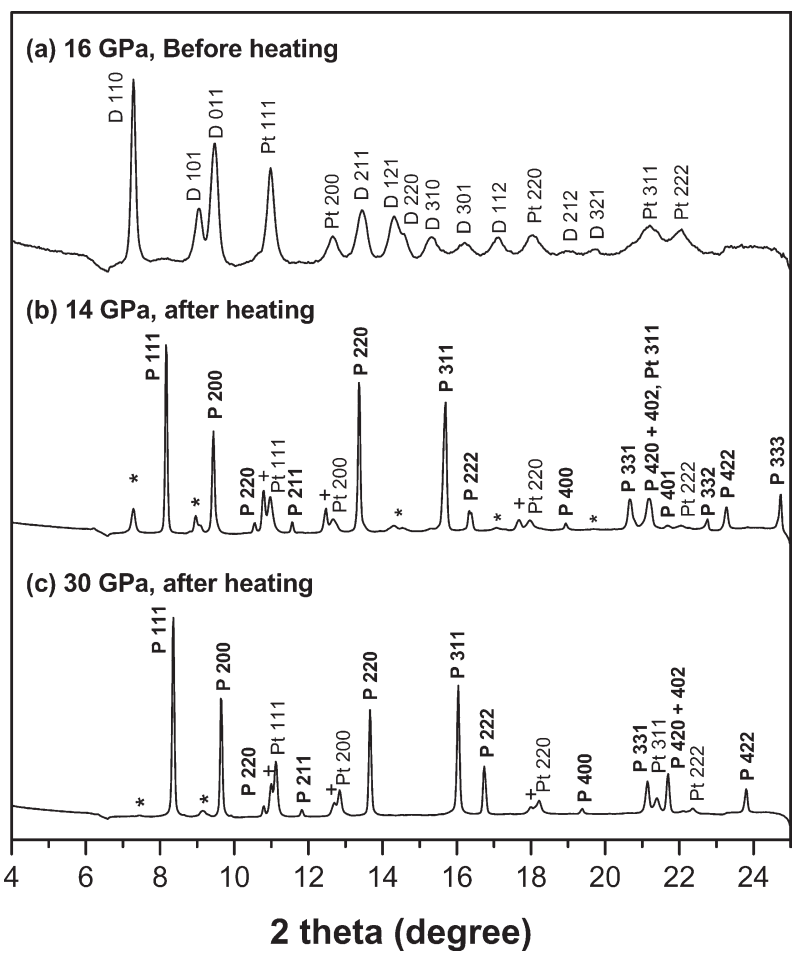

Figure 1. X-ray diffraction patterns obtained before heating (a), and after heating (b), (c) at high pressure. Abbreviations are as follows: $\mathrm{D}$, distorted rutile-type $\mathrm{InOOH}$; Pt, platinum; P, pyritetype $\mathrm{InOOH} ;$, unreacted starting material; +, unknown cubic phase.

tural with $\delta$-AlOOH having strong hydrogen bonds (Lehmann et al., 1970). The hydrogen bond geometry consists of the $\mathrm{O}-\mathrm{O}$ distance of $2.54 \AA$ and the $\mathrm{O}-\mathrm{H}$ distance of $1.08 \AA$.

\section{EXPERIMENTAL}

Two starting materials were used, reagent grade of $\operatorname{In}(\mathrm{OH})_{3}$ and distorted rutile-type $\mathrm{InOOH} . \mathrm{In}(\mathrm{OH})_{3}$ takes $\mathrm{ReO}_{3}$-type structure at ambient conditions which is described as an A-site deficient hydroxy-perovskite structure (Mullica et al., 1979). The distorted rutile-type InOOH was synthesized using cubic-anvil type high pressure apparatus at ISSP. $\mathrm{In}(\mathrm{OH})_{3}$ was loaded into a gold capsule and placed into a cylindrical graphite heater with a insulator of boron nitride sleeve. It was kept at $4 \mathrm{GPa}$ and $873 \mathrm{~K}$ for $1 \mathrm{~h}$. Recovered sample was analyzed by micro focused $\mathrm{X}$-ray diffractometer with a rotating $\mathrm{Cr}$ anode operated at $40 \mathrm{kV}$ and $200 \mathrm{~mA}$. It was confirmed to have distorted rutile-type structure with lattice constants of $a=5.267$ (3), $b=4.5698$ (3), $c=3.282$ (2) A. Both starting materials were grounded in the agate mortar and mixed with platinum black, which serves as a laser absorber and pressure standard, and loaded into a hole of a rhenium gasket of diamond anvil cells.

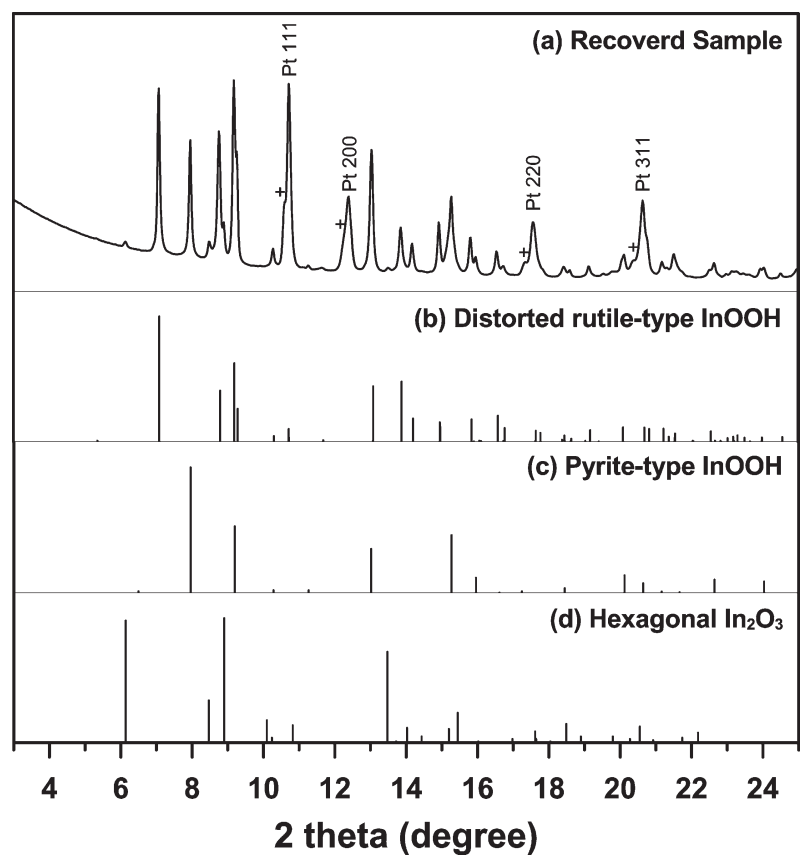

Figure 2. X-ray diffraction pattern of (a) recovered sample obtained at ambient conditions and the calculated peak positions and intensities of (b) distorted rutile-type $\mathrm{InOOH}$, (c) pyrite-type InOOH (Space group $P 2_{1} 3$, Tsuchiya et al., 2007), and (d) hexagonal $\mathrm{In}_{2} \mathrm{O}_{3}$ (PDF no. 01-073-1809). Abbreviations are the same as Figure 1.

Angle dispersive $\mathrm{X}$-ray diffraction experiment using Imaging Plate (IP) was conducted at BL13A beamline of KEK, Photon Factory in Tsukuba, Japan. Monochromatic X-ray of approximately $29 \mathrm{keV}$ was collimated into $30-50 \mu \mathrm{m}$ in a diameter. Pressure was calculated from the unit cell volume of platinum using equation of state of Holmes et al. (1989) within the margin of error less than 2 GPa. The sample was heated by a multimode Nd:YAG laser or fiber laser for 10-20 min. The laser spot was slowly scanned during heating to heat the entire sample. Temperature was measured by the spectroradiometric method and its fluctuation was 100-200 K. After the sample was quenched to room temperature, $\mathrm{X}$-ray diffraction patterns were corrected at high pressure to determine the synthesized phase with an exposure time of 10-15 min. The one-dimensional profile was obtained by integrating the two-dimensional diffraction image.

\section{RESULT AND DISCUSSION}

In the run using $\mathrm{InOOH}$ as a starting material, sample was compressed to $16 \mathrm{GPa}$ and then heated at $1300 \mathrm{~K}$. Distorted rutile-type $\mathrm{InOOH}$ was observed before the heating although peaks were broadened considerably because of the nonhydrostaticity (Fig. 1a). After heating, the diffraction peaks of distorted rutile-type InOOH almost disap- 
Table 1. Observed and calculated $d$-value of pyrite-type $\mathrm{InOOH}$ and platinum at $30 \mathrm{GPa}$

\begin{tabular}{|c|c|c|c|c|c|c|c|}
\hline \multirow{2}{*}{$d_{\text {obs }}$} & \multirow{2}{*}{$I / I_{0}$} & \multicolumn{3}{|c|}{ Pyrite } & \multicolumn{3}{|c|}{ Platinum } \\
\hline & & $d_{\text {calc. }}$ & $d_{\text {obs. }}-d_{\text {calc. }}$ & $h k l$ & $d_{\text {calc. }}$ & $d_{\text {obs. }}-d_{\text {calc. }}$ & $h k l$ \\
\hline $3.2859^{*}$ & $>1$ & & & & & & \\
\hline 2.9277 & 100 & 2.9264 & 0.0013 & 111 & & & \\
\hline $2.6710^{*}$ & 3 & & & & & & \\
\hline 2.5355 & 61 & 2.5343 & 0.0012 & 200 & & & \\
\hline 2.2674 & 5 & 2.2668 & 0.0006 & 210 & & & \\
\hline $2.2266^{* *}$ & 14 & & & & & & \\
\hline 2.2006 & 27 & & & & 2.2003 & 0.0003 & 111 \\
\hline 2.0705 & 3 & 2.0693 & 0.0012 & 211 & & & \\
\hline $1.9304^{* *}$ & 5 & & & & & & \\
\hline 1.9070 & 12 & & & & 1.9056 & 0.0004 & 200 \\
\hline 1.7930 & 52 & 1.7921 & 0.0009 & 220 & & & \\
\hline 1.5287 & 62 & 1.5283 & 0.0004 & 311 & & & \\
\hline 1.4649 & 23 & 1.4632 & 0.0006 & 222 & & & \\
\hline $1.3632^{* *}$ & 3 & & & & & & \\
\hline 1.3476 & 6 & & & & 1.3474 & 0.0002 & 220 \\
\hline 1.2673 & 3 & 1.2672 & 0.0001 & 400 & & & \\
\hline 1.1627 & 15 & 1.1628 & -0.0001 & 331 & & & \\
\hline 1.1491 & 7 & & & & 1.1491 & 0.0000 & 311 \\
\hline 1.1333 & 19 & 1.3334 & 0.0001 & $\begin{array}{c}420 \\
+002\end{array}$ & & & \\
\hline $1.1127^{* *}$ & 1 & & & & & & \\
\hline 1.1000 & 2 & & & & 1.1002 & -0.0002 & 222 \\
\hline 1.0343 & 11 & 1.0346 & -0.0002 & 422 & & & \\
\hline
\end{tabular}

peared and many new sharp peaks appeared. The remained small peaks would be scattered from the unheated sample near the diamond anvils (Fig. 1b). The new peaks were well explained by pyrite-type phase that was theoretically predicted (Tsuchiya et al., 2008). Most of the peaks are explained by fcc structure. However, the existence of 210 and 211 reflections suggests that oxygen sublattice is not fcc structured as fluorite is, but is explained by pyrite-type structure. It is indexed as a cubic lattice with $a=5.185$ (2) $\AA$ and a unit cell volume was determined to be 139.4 (1) $\AA^{3}$ at $14 \mathrm{GPa}$. Pyrite-type InOOH remained stable at $30 \mathrm{GPa}$ after heating at $1700 \mathrm{~K}$. The lattice constant and unit cell volume at $30 \mathrm{GPa}$ were $a=5.0687(6) \AA$ and $V=130.22(4) \AA^{3}$, respectively.

After the sample was recovered to ambient condition, the intensity of diffraction peaks from the distorted rutile-type InOOH increased and those from the pyritetype InOOH became relatively weak, suggesting that the pyrite-type phase partially retransformed back to distorted rutile-type InOOH (Fig. 2). The lattice constant and unit cell volume of pyrite-type InOOH at ambient conditions was determined to be $a_{0}=5.3151(8) \AA$ and $V_{0}=150.15$ (7) $\AA^{3}$. The densities of distorted rutile-type and pyritetype InOOH were $6.22 \mathrm{~g} / \mathrm{cm}^{3}$ and $6.54 \mathrm{~g} / \mathrm{cm}^{3}$, respectively; therefore the density increase is about $5 \%$. Some of pyrite-type high-pressure polymorphs of $\mathrm{AX}_{2}$-type components such as $\mathrm{MgF}_{2}$ and $\mathrm{SnO}_{2}$ transforms into $\alpha-\mathrm{PbO}_{2}{ }^{-}$ type phase during decompression (Haines and Léger, 1997, Haines et al., 2001). These compounds have intermediate $\alpha-\mathrm{PbO}_{2}$-type phase between rutile-type and pyrite-type structures. However, no evidence of such transformation was observed in $\mathrm{InOOH}$. Small amount of hexagonal corundum-type $\operatorname{In}_{2} \mathrm{O}_{3}$ phase was observed. Probably it was formed by the dehydration of $\mathrm{InOOH}$ at high temperature region during heating. We note that some unidentified peaks were also observed after heating at high pressure and in the recovered sample (Figs. 1b, 1c and Fig. 2). All of them were observed next to the peaks of platinum at lower 2-theta angle side and could be indexed by a cubic lattice, suggesting the possibility that a partial reaction of platinum with starting material has occurred. Although the nature of the reaction remains unclear, it would not affect the pressure determination using the platinum equation of state, since the lattice constant of the recovered platinum at ambient condition $(a=$ 3.9433(4) §) was not significantly different from that of pure platinum.

Formation of pyrite-type InOOH was also confirmed in the run using $\operatorname{In}(\mathrm{OH})_{3}$ as a starting material. $\operatorname{In}(\mathrm{OH})_{3}$ underwent amorphization during compression and only platinum was found in the diffraction pattern before heating. Pyrite-type $\mathrm{InOOH}$ and $\mathrm{H}_{2} \mathrm{O}$-Ice were formed at 22 GPa after heating at $1500 \mathrm{~K}$.

Present experimental study is in agreement with the theoretical study, which has predicted that pyrite-type InOOH becomes stable above $15 \mathrm{GPa}$ (Tsuchiya et al., 2008). They also suggested that the hydrogen locates at the midpoint between two oxygen atoms forming symmetric hydrogen bond in pyrite-type $\mathrm{InOOH}$ above 30 $\mathrm{GPa}$. The space group of pyrite-type InOOH differs between asymmetric and symmetric hydrogen bond models, which is assumed to be $P 2_{1} 3$ and $P a \overline{3}$, respectively. However, it was difficult to distinguish these two structural models by the present study because of a subtle difference of X-ray diffraction patterns of $P 2_{1} 3$ and $P a \overline{3}$ models. Further study such as Raman spectroscopic or neutron diffraction study is needed to examine whether the hydrogen bond in pyrite-type $\mathrm{InOOH}$ is asymmetric or symmetric. 


\section{ACKNOWLEDGMENTS}

A.S. was supported by Research Fellowships of the Japan Society for the Promotion of Science for Young Scientists.

\section{REFERENCES}

Chenavas, J., Joubert, J.C., Capponi, J.J. and Marezio, M. (1973) Synthese de nouvelles phases denses d'oxyhydroxydes $\mathrm{M}^{3+} \mathrm{OOH}$ des metaux de la premiere serie de transition, en milieu hydrothermal à tres haute pression. Journal of Solid State Chemistry, 6, 1-15.

Christensen, A.N. (1971) Hydrothermal preparation of some oxides and some oxide hydroxides at temperatures up to $900{ }^{\circ} \mathrm{C}$ and pressures up to $80 \mathrm{~kb}$. Materials Research Bulletin, 6, 691-698.

Haines, J. and Léger, J.M. (1997) X-ray diffraction study of the phase transitions and structural evolution of tin dioxide at high pressure: Relationships between structure types and implications for other rutile-type dioxides. Physical Review B, $55,11144-11154$.

Haines, J., Léger, J.M., Gorelli, F., Klug, D.D., Tse, J.S. and Li, Z.Q. (2001) X-ray diffraction and theoretical studies of the high-pressure structures and phase transitions in magnesium fluoride. Physical Review B, 64, 134110.

Holmes, N.C., Moriarty, J.A., Gathers, G.R. and Nellis, W.J. (1989) The equation of state of platinum to $660 \mathrm{GPa}(6.6$ Mbar). Journal of Applied Physics, 66, 2962-2967.

Kingma, K.J., Cohen, R.E., Hemley, R.J. and Mao, H.K. (1995) Transformation of stishovite to a denser phase at lower-mantle pressures. Nature, 374, 243-245.

Kuwayama, Y., Hirose, K., Sata, N. and Ohishi, Y. (2005) The pyrite-type high-pressure form of silica. Science, 309, 923-925.

Léger, J.M., Haines, J. and Pereira, A.S. (1998) Structural investigations under high pressure. Review of High Pressure Science and Technology, 7, 295-297.

Lehmann, M.S., Larsen, F.K., Poulsen, F.R., Christensen A.N. and Rasmussen S.E. (1970) Neutron and X-ray crystallographic studies on indium oxide hydroxide. Acta Chemica Scandinavica, 24, 1662-1670.

Mullica, D.F., Beall, G.W., Milligan, W.O., Korp, J.D. and Bernal, I. (1979) The crystal structure of cubic $\mathrm{In}(\mathrm{OH})_{3}$ by X-ray and neutron diffraction methods. Journal of Inorganic and Nuclear Chemistry, 41, 277-282.

Murakami, M., Hirose, K., Ono, S. and Ohishi, Y. (2003) Stability of $\mathrm{CaCl}_{2}$-type and $\alpha-\mathrm{PbO}_{2}$-type $\mathrm{SiO}_{2}$ at high pressure and temperature determined by in-situ X-ray measurements. Geophysical Research Letters, 30, 1207, doi:10.1029/ 2002GL016722.

Ohtani, E, Litasov, K., Suzuki, A. and Kondo, T. (2001) Stability field of new hydrous phase, $\delta-\mathrm{AlOOH}$, with implications for water transport into the deep mantle. Geophysical Research Letters, 28, 3991-3993.

Sano, A., Ohtani, E., Kondo, T., Hirao, N., Sakai, T., Sata, N., Ohishi, Y. and Kikegawa, T. (2008) Aluminous hydrous mineral $\delta$-AlOOH as a carrier of hydrogen into the core-mantle boundary. Geophysical Research Letters, 35, L03303, doi:10.1029/2007GL031718.

Suzuki, A., Ohtani, E. and Kamada, T. (2000) A new hydrous phase $\delta$-AlOOH synthesized at $21 \mathrm{GPa}$ and $1000^{\circ} \mathrm{C}$. Physics and Chemistry of Minerals, 27, 689-693.

Tsuchiya, J., Tsuchiya, T., Tsuneyuki, S. and Yamanaka, T. (2002) First principles calculation of a high-pressure hydrous phase, $\delta$-AlOOH. Geophysical Research Letters, 29, 1909, doi:10.1029/2002GL015417.

Tsuchiya, J., Tsuchiya, T., Sano, A. and Ohtani, E. (2008) First principles prediction of new high-pressure phase of $\mathrm{InOOH}$. Journal of Mineralogical and Petrological Sciences, 103, 116-120.

Vanpeteghem, C.B., Sano, A., Komatsu, K., Ohtani, E. and Suzuki, A. (2007) Neutron diffraction study of aluminous hydroxide $\delta$-AlOOH. Physics and Chemistry of Minerals, 34, 657-661.

Manuscript received October 22, 2007

Manuscript accepted February 2, 2008

Manuscript handled by Yasuhiro Kudoh 